Session 2258

\title{
Belshazzar: A Simple Tool for Creating and Publishing Voice-Annotated Drawings on the Web
}

\author{
Thomas K. Miller III, Stephen J. Walsh, Hollylynne Stohl, and Leigh Ann Haefner \\ North Carolina State University
}

Engineering faculty are often discouraged by the challenges of participating in distance learning, or incorporating on-line learning approaches in their courses. A particularly important challenge is the time-, skill-, and resource-intensive endeavor of producing web-based content for students. This is particularly true in engineering and scientific and mathematically-based disciplines, where much of the content involves representing concepts through diagrams and equations. While the tools for electronic production of text-based content are well-developed and very easy to use, the production of more technologically sophisticated content needed to represent engineering concepts is much more challenging. For example, suppose a student in an introductory circuits course is having trouble conceptualizing reducing a circuit to its Thevenin equivalent. With pencil and paper during face-to-face interaction, the instructor could illustrate and explain the problem solving process. In contrast, producing a web-based resource to accomplish the same purpose would be a very time-consuming ordeal, typically requiring skill with sophisticated software tools.

At North Carolina State University we have developed a simple tool, we call Belshazzar, that allows an instruct or to dynamically capture the problem solving process in action with a voiceannotated representation. This information is captured in real time on a PC as an instructor explains the process using pen and paper. With one click this process can be replayed, and with a second click published to the Web as a Flash ${ }^{\mathrm{TM}}$ movie. The result is a web page where the voiceannotated representation is reproduced in real time for the student. Because we capture and render pen stroke information, the movies are high resolution, yet low bandwidth (they work well over a 56K modem link).

\section{Instructional Underpinnings}

Communication about scientific, mathematical and highly technical concepts is connected to being able to represent ideas in a form that can be used as a "didactical object" as something that can be a focus of conversation. An object (e.g., drawing, graph, diagram) is not didactic in and of itself. It becomes didactic because of the conversations it can enable between persons who have conceived the object as something important to talk about. In addition, it is not only the object that can enable such conversations. The process of creating the object can also be a focus for conversation and reflection. Thus, it is important for students to be able to experience the process of creating a representation (representing) as well as the finished product (a representation). A tool like Belshazzar can help students experience both the process and product aspect and listen 
to an instructor's explanation of the object. Although at first this web-based object does not allow for a two-way conversation between instructor and student, it certainly provides a didactical system for self reflection that a student can replay numerous times

The process of creating such a representation for students can provide appropriate scaffolds that can build on learners' current understandings and take them through a process that builds on prior understanding. Scaffolding can be described as the mechanism through which social interaction facilitates cognitive development within the learner's zone of proximal development. ${ }^{10}$ This often occurs when a novice works closely with a more capable other in joint problem solving. The scaffolding is often temporary and the support enables learners to do what they would otherwise be unable to do alone. Recent work in technology-supported environments illustrates how the concept of scaffolding has expanded to include many new forms of support. ${ }^{7}$ For example, software can facilitate organization, annotation ${ }^{2}$ and reflection. ${ }^{3,5,6}$ With respect to Belshazzar, because of the visual and verbal aspects of the tool, it acts as a scaffold associated with instruction. ${ }^{1,8}$ Instructional scaffolds can be considered in terms of modeling, questioning, providing feedback and direction with regard to strategies and attention to particulars, as well as offering explanations. ${ }^{8}$ As stated previously, the power of a tool like Belshazzar is in potential to scaffold the learner as they experience the process of creating the representation while simultaneously supporting developing understandings of the product of the representation.

\section{Prototyping the Tool}

The genesis of Belshazzar was inspired by advanced technologies being developed by IBM in 2000. The pen-computing group had developed the CrossPad 2 for Cross, Inc.. This device holds a standard $8 \frac{1}{2} \times 11$ notepad and uses a sensor pen which allows the precise position of the pen to be sensed when the tip is on or near the surface of the notepad. A microswitch in the pen tip activates when the tip touches the paper. This combination of sensors allows pen strokes to be recorded, as well as movement of the pen near the paper, but not touching.

What is actually recorded when a user writes on the notepad of the CrossPad2 are pen strokes and time stamps. This information is sufficient to allow the reconstruction of a drawing on a computer screen in "real time," (i.e., the strokes constituting the drawing appear on the screen with the same timing as when they were actually drawn on the paper). Miller (first author) wanted to synchronize CrossPad2's data capture with a voice recording on an attached PC to create a voice-annotated drawing that could be streamed over the Internet. IBM donated five CrossPad 2 units to support the development project as a design project completed by undergraduates in the Department of Computer Science. The initial design objectives for this product were:

1. Ease of use. The system must be extremely easy to use. This implies a simple and intuitive user interface, with no "bells and whistles."

2. One-click publishing with an integrated FTP client. The system should include an integrated FTP client so that the voice-annotated recordings can be uploaded to a server without the user having to save files and use a general purpose FTP package to upload them. 
3. Low bandwidth. While broadband connectivity is advancing rapidly, it is by no means ubiquitous. Playback of voice-annotated recordings must work well over a 56K modem link.

4. Platform-neutral playback. The voice-annotated recordings must play on all common computing platforms that students might use. The minimum requirement for the set of playback platforms was Windows, Macintosh, Linux and Unix.

5. No custom client software. Playback on the client must be initiated via a web page on a standard web browser, and must be enabled through software automatically downloaded from the server (i.e., a Java applet), or through a "common off the shelf" (COTS) package such as Real Player ${ }^{\mathrm{TM}}$.

The first design attempt by the students proved very frustrating. There were bugs in the CrossPad 2 firmware that could not be resolved, and missing functionality in the API. Initially, IBM was very helpful in trying to assist us to resolve these issues. However, in the midst of the prototyping, IBM made a business decision to abandon the CrossPad2 product and we were left on our own to deal with the technical problems. A prototype was developed, including a custom Java applet for playback. Unfortunately, the firmware bugs and limitations rendered the prototype unusable. The Java applet worked, but there were issues with download time and performance.

\section{Second Prototype}

A second design team took over the project the next semester, beginning from a set of lessons learned from the first team. A new idea was to use Flash ${ }^{\mathrm{TM}}$ as a web-based player, building a Flash movie from the recorded stroke information and a simultaneously captured sound file. Flash does a good job of anti-aliasing the lines drawn on the screen, so the appearance of the output was far superior to what we were able to obtain with Java. Sound quality was also much better, and the progressive download capability of Flash provided a streaming effect, eliminating wait time for the recording to be downloaded. Unfortunately, the API shortcomings still represented an insurmountable barrier from a functionality and usability perspective.

A significant contribution of the second semester team was to name the project. The name selected was "Belshazzar," from the Bible verse in which handwriting magically appeared on a wall.

\section{The Latest Iteration: Mi-Co to the Rescue}

Our fortune changed considerably when it was learned that Mi-Co (www.mi-corporation.com), a start-up company specializing in pen-based computing solutions, had obtained the rights to the abandoned IBM technology for the CrossPad2. They became interested in our project and helped us get raw data for pen position on the output port. This was the breakthrough needed to achieve all of the original design objectives. Since the design was essentially done, the development work required to turn Belshazzar into a usable tool was not suitable for a subsequent semester design project. The effort continued by hiring computer science students supported by NC State University's Office of Distance Education and Learning Technology Applications (DELTA). The system is currently used in limited production by faculty at NC State. 


\section{System Description}

The complete Belshazzar system setup, which consists of a tablet with pen, microphone, and a PC or laptop running the Windows 98 or newer operating system, is depicted in Figure 1. The Belshazzar software, which is visible on the laptop screen, is shown in detail in Figure 2. The style of the user interface is styled after the controls of a simple VCR to provide a familiar and intuitive paradigm for the user (Play, Record, Pause) as well as new button controls. The "New Page" feature allows a recording to include a two or more page drawing. The "Upload" button uploads the current recording using a built-in FTP client to a pre-specified location. The two rightmost buttons are "Save" and "Save As" for saving the recording as a Flash movie on the local disk.

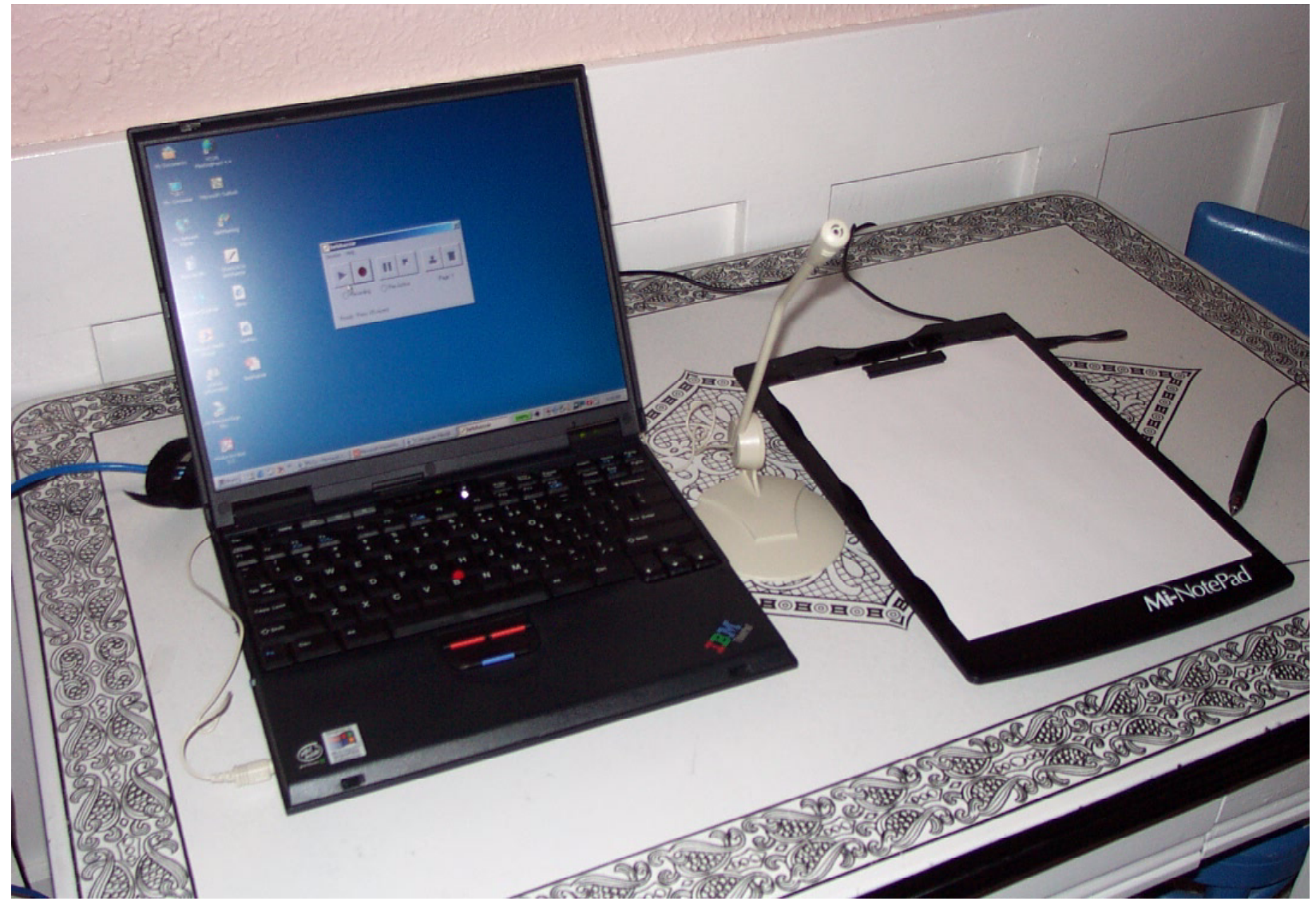

Figure 1. Complete Belshazzar system setup.

The user interface provides two "virtual LED's" for user feedback. The "Pen Active" LED lights up when the tablet detects that the pen is in close proximity to the pad. This signals the user that the software and hardware is working properly. The "Recording" LED signals the user that Belshazzar is recording sound and pen strokes. While explaining the diagram being drawn, it turns out to be very natural for the user to point to what he or she is talking about with the tip of the pen. This is recorded in the Flash movie as a red "laser dot" which indicates to the student where the pen is pointing when no drawing is currently taking place. This will only occur when 
the pen tip is in close proximity to the pad during recording, such that the "Pen Active" light is on. This turns out to be a very convenient and natural mechanism to create a focus for didactic purposes when the movie is played back

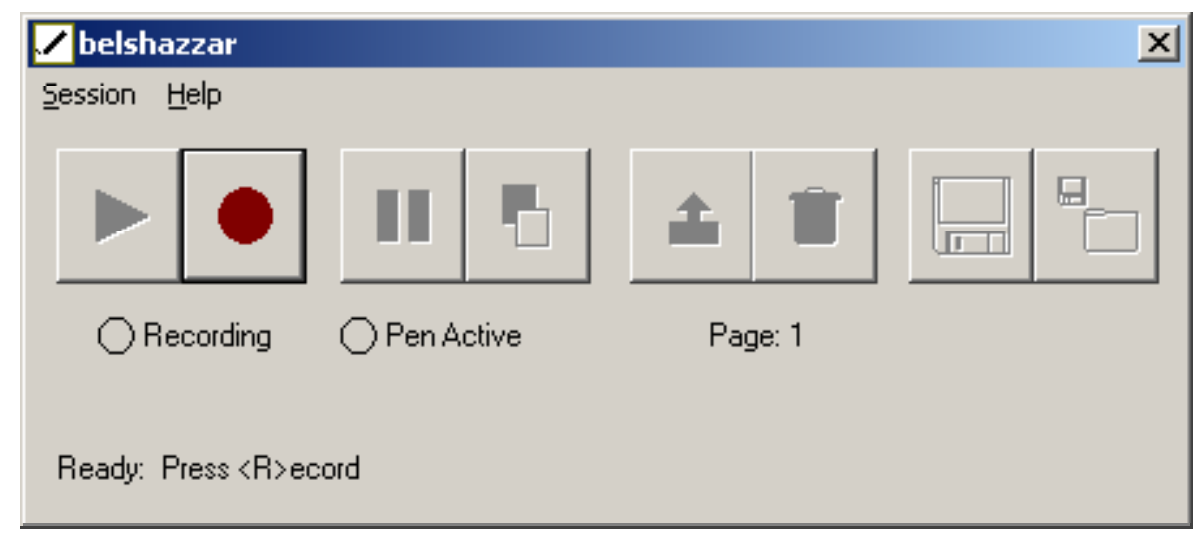

Figure 2. The Belshazzar user interface.

When the recording is complete, the user clicks "Pause/Stop" button. The "Play" button will compile the sound and stroke files into a Flash movie and play it back, exactly as it will appear to the student. If the user is satisfied with the recording, the "Upload" button is clicked to publish the movie on the web. A Belshazzar Flash movie is shown playing in a web browser in Figure 3. Note that a set of controls including "Play," "Stop," and "Restart" are provided at the bottom of the page.

\section{Related Approaches}

Most web conferencing and "virtual classroom" systems provide the capability to synchronize a voice stream with drawings on an electronic whiteboard. A number of these systems, such as Centra Symposium (www.centra.com), Horizon Live (www.horizonlive.com), and the Distance Education Teaching Assistant (DETA, www4.ncsu.edu/ tkm/deta) ${ }^{4}$ support the archiving and ondemand playback of the synchronized streams. However, these systems differ substantially from Belshazzar in a number of respects. First, they are primarily designed for synchronous conferencing as compared to the asynchronous design of Belshazzar. Further, these tools are much more complex with a higher learning curve and support costs. Unlike Belshazzar, they require specialized servers and client software for playback of archived sessions. The systems and support requirements make them impractical for the types of applications for which Belshazzar is designed.

\section{User Experience}

Walsh (second author) teaches a distance education section of a circuit analysis course for the Electrical and Computer Engineering department of NC State's College of Engineering. The section is composed of students from NC State University in Raleigh, UNC Asheville in Asheville, and Lenoir Community College in Kinston. This course is taught from a studio at NC State University where the NC State students are present, and it is received live at both UNC Asheville 
and Lenoir Community College.

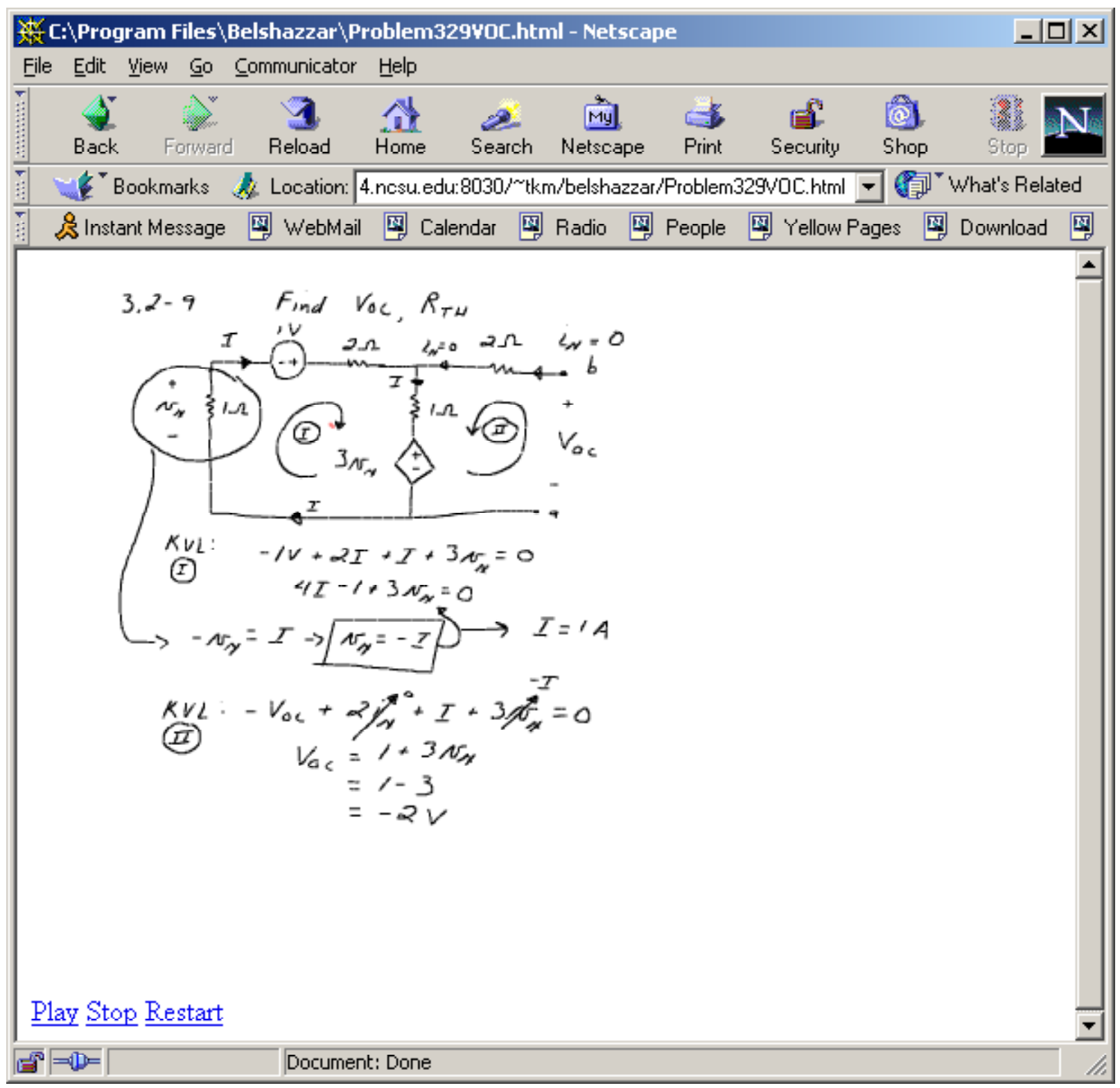

Figure 3. A Belshazzar Flash movie playing in Netscape.

Many of the students do not grasp concepts the first time they are presented and discussed in class. The model of distance education creates physical and time constraints that do not allow student to have much interaction with the instructor. Belshazzar has helped solve the problem of individual tutoring while providing students a solution to their educational needs. By using Belshazzar, the instructor was able to quickly and efficiently create a tutorial that allowed the students to listen, watch, and reflect upon a the process of solving a circuit problem as many times as they wish by simply playing the Belshazzar Flash file posted on the course web site. The 
reaction from students was extremely positive, to the extent that they encouraged the instructor to use the tool more heavily in the class. While Belshazzar does not provide highly polished graphics and video, the students valued the tool as providing an object to help them learn a process and understand a final product, with the capability of reviewing this process as many times as they needed.

From the instructor's perspective, there was benefit in using Belshazzar to rehearse individual problems multiple times, since regenerating a single problem takes just a few minutes. In addition, the time taken to create the Flash file using Belshazzar was viewed as much more efficient than going over the same concept with different students at different times.

\section{Current Status and Future Plans}

Belshazzar is currently at software revision 1.1. Tablets have been provided to selected instructors at NC State who are teaching on-line courses, and who are willing to provide feedback on Belshazzar to improve future versions. Work is in progress on a new sound recording methodology to improve synchronization with the pen strokes. Work is also underway to improve the look and feel of the playback interface. Mi-Co has expressed interest in working with us to license and commercialize Belshazzar. A few examples of Beshazzar Flash movies are available on the web at http://www4.ncsu.edu/ tkm/belshazzar.

Faculty at NCSU have begun to envision a variety of uses for Belshazzar. Within a distance education setting, students at remote sites would be able to use the Belshazzar to quickly create a diagram and share it across sites that could encourage cross-site dialogue about the didactic object created. Another use could be as an assessment and research tool. If students solve a selected task using the Belshazzar system, a teacher or researcher would have a rich media file that captures the essence of a student's problem solving capabilities much more so than viewing their finished product on an exam. The media file would provide a window into their thinking processes that may help instructors and researchers interpret their intent, understandings, and cognitive difficulties.

\section{References}

1. Beed, P.L., Hawkins, E.M., \& Roller, C.M. (1991). Moving learners toward independence: The power of scaffolded instruction. The Reading Teacher, 44 (9), 648-655.

2. Bell, P. (1997). Using argument representations to make thinking visible for individuals and groups.

Proceedings of CSCL: The Second International Conference on Computer Support for Collaborative Learning. Toronto, Canada.

3. Davis, E., \& Linn, M. (2000). Scaffolding students' knowledge integration: prompts for reflection in KIE. International Journal of Science Education, 22 (8), 819-837.

4. Davis, K., Miller, T., \& Price, C. (2000). Using Linux and Mbone for Distance Education. The Linux Journal, vol. 78.

5. Haefner, L., Zembal-Saul, C., \& Avraamidou, L. (2002). Supporting prospective elementary teachers developing scientific explanations using Progress Portfolio. Paper presented and the annual meeting of the National Association of Research in Science Teaching, New Orleans, LA. 
6. Land, S., \& Zembal-Saul, C., (2001). Scaffolding reflection and the revision of explanations during projectbased learning: An investigation using Progress Portfolio. Paper presented at the annual meeting of the American Educational Research Association, Seattle, WA.

7. McLoughlin, C. (1999). Scaffolding: Applications to learning in technology supported environments. Paper presented at the World Conference on Educational and Multimedia and Hypermedia \& World Conference on Educational Telecommunications, Seattle, WA.

8. Oliver, K. (1996). Realizing the potential of scaffolded instruction in situated learning environments: Lessons from a formative assessment. (ERIC Document Reproduction Service No. ED413310): University of Georgia.

9. Thompson, P. W. (2002). Didactic objects and didactic models in radical constructivism. In K. Gravemeijer, R. Lehrer, B. van Oers, \& L. Verschaffel (Eds.), Symbolizing, Modeling, and Tool Use In Mathematics Education (pp. 191-212). Dordrecht, The Netherlands: Kluwer Academic Publishing.

10. Vygotsky, L.S. (1978). Mind in Society: The development of higher psychological processes. Cambridge: Harvard University Press.

THOMAS K. MILLER III

is a Professor of Electrical and Computer Engineering at North Carolina State University and Director of the Engineering Entrepreneurs Program, which he founded in 1993. He received the $\mathrm{PhD}$ in Biomedical Engineering and Mathematics from the University of North Carolina in 1982, and is a member of the Academy of Outstanding Teachers at NC State. He is currently serving as Vice Provost for Distance Education and Learning Technology Applications.

\section{STEPHEN J. WALSH}

is a Visiting Assistant Professor of Electrical and Computer Engineering at North Carolina State University and Entrepreneur in Residence for the Engineering Entrepreneurs Program. Previously, he was co-founder and CEO of BOPS, Inc. He teaches courses in circuits and engin eering analysis to both campus-resident and distance learning students.

HOLLYLYNE STOHL

is an Assistant Professor of Mathematics Education in the Department of Mathematics, Science, and Technology Education at North Carolina State University. She received her Ph.D. in mathematics education from the University of Virginia. Dr. Stohl's research focus is on the use of technology tools in students' understanding of mathematics and the design of mathematics software, particularly for statistics and probability. She serves as a faculty advisor for the Engineering Entrepreneurs Program.

\section{LEIGH ANN HAEFNER}

is an Assistant Professor of Science Education in the Department of Mathematics, Science and Technology Education at North Carolina State University. She received her Ph.D. in science education from Penn State University. Dr. Haefner's research focus is on preservice teachers' developing understandings of science inquiry with specific attention to scientific explanation and argument. Her research also includes the role of technological scaffolds to support scientific argument and explanation building. 